\title{
Comparison of voluntary food intake and palatability of commercial weight loss diets in healthy dogs and cats
}

Marie Anne Hours ${ }^{1}$, Emmanuelle Sagols ${ }^{1}$, Ariane Junien-Castagna', Alexandre Feugier ${ }^{1}$, Delphine Moniot ${ }^{1}$, Ingrid Daniel' ${ }^{1}$, Vincent Biourge ${ }^{1}$, Serisier Samuel ${ }^{2,4}$, Yann Queau ${ }^{1}$ and Alexander J. German ${ }^{3,5^{*}}$

\begin{abstract}
Background: Obesity in dogs and cats is usually managed by dietary energy restriction using a purpose-formulated weight loss diet, but signs of hunger and begging commonly occur causing poor owner compliance. Altering diet characteristics so as to reduce voluntary food intake (VFI) can improve the likelihood of success, although this should not be at the expense of palatability. The aim of the current study was to compare the VFI and palatibility of novel commercially available canine and feline weight loss diets.

Methods: The relative performance of two canine ( $\mathrm{C} 1$ and $\mathrm{C} 2$ ) and two feline (F1 and F2) diets was assessed in groups of healthy adult dogs and cats, respectively. Diets varied in energy, protein, fibre, and fat content. To assess canine VFI, 12 (study 1) and 10 (study 2) dogs were offered food in 4 meals, for 15 min on each occasion, with hourly intervals between the meals. For feline VFI, 12 cats were offered food ad libitum for a period of $18 \mathrm{~h}$ per day over 5 consecutive days. The palatability studies used separate panels of 37 dogs and 30 cats, with the two diets being served, side-by-side, in identical bowls.

Results: In dogs, VFI was significantly less for diet C1 than diet C2 when assessed on energy intake (study 1, 42\% less, $P=0.032$; study 2, 28\% less, $P=0.019$ ), but there was no difference in gram weight intake (study $1: P=0.964$; study 2: $P=0.255)$. In cats, VFI was $17 \%$ less for diet F1 than diet F2 when assessed by energy intake $(P<0.001)$, but there was again no difference in gram weight $(P=0.207)$. There was no difference in palatability between the two canine diets $(P=0.490)$, whilst the panel of cats diet preferred F1 to F2 $(P<0.001)$.

Conclusion: Foods with different characteristics can decrease VFI without affecting palatability in both dogs and cats. The effects seen could be due to decreased energy content, decreased fat content, increased fibre content, different fibre source, and increased protein content. Further studies are now needed to determine whether similar findings occur in obese dogs and cats on controlled weight loss programmes.
\end{abstract}

Keywords: Obesity, Canine, Appetite, Weight loss

\section{Background}

Obesity is now a common medical disorder in both dogs and cats, and has various effects on the health of animals of both species [1-5]. Controlled weight loss has been shown to have a number of benefits in previously obese dogs, including improved mobility [6], improved respiratory

\footnotetext{
* Correspondence: ajgerman@liverpool.ac.uk

${ }^{3}$ Institute of Ageing and Chronic Disease, University of Liverpool, Leahurst

Campus, Chester High Road, Neston, Wirral CH64 7TE, UK

${ }^{5}$ Institute of Veterinary Science, University of Liverpool, Leahurst Campus,

Chester High Road, Neston CH64 7TE, UK

Full list of author information is available at the end of the article
}

function [4], resolution of metabolic disturbances [7, 8], and improved quality of life [5]. Dietary energy restriction using a purpose-formulated diet is the most common approach for inducing weight loss, and such strategies are usually very successful in experimental trials in both dogs [9-11] and cats [12, 13]. However, the same strategies do not perform as well in a clinical setting, for obese clientowned pets, with slower rates of weight loss observed despite marked energy restriction [14-17]. Further, many dogs and cats do not successfully reach their target weight, and this is most often because owners struggle to comply with 
the programme ultimately deciding to stop $[18,19]$. A common problem that owners encounter is the fact that dietary energy restriction causes hunger, which causes increased begging and scavenging activity in their dog or cat. Such behaviour can be difficult for the owner to resist, ultimately leading to poor compliance. Indeed, recent studies have indicated that many owners feed additional food during a controlled weight loss programme despite veterinary recommendations $[14,15]$.

Food manufacturers can alter a range of dietary characteristics, and such changes can affect voluntary food intake (VFI). For example, a weight management diet can be changed so as to reduce VFI, and such a modification should increase the likelihood of success, provided that it does not adversely affect palatability and, therefore, overall diet acceptance. Approaches that can be used in dogs and cats include decreasing nutrient density, for instance by expanding kibble volume with air [20] or water [21], and altering the macronutrient content of the diet by increasing protein and/or fibre content [22, 23]. In addition to caloric dilution, adding dietary water can increase voluntary physical activity and may have added benefits for weight loss [21]. With regard to macronutrient content, recent studies have indicated that a diet containing increased amounts of both protein and fibre are more effective at reducing VFI than diets containing increased amounts of these macronutrients individually [22], and have shown that such diets lead to improved outcomes of weight loss in obese pet dogs [17]. In cats, the ideal balance of protein and fibre is more difficult to optimise because very high protein diets can actually stimulate VFI in cats, whilst very high fibre diets can be unpalatable [23]. Despite this, dry diets that combine moderately increased protein and fibre content are better at reducing begging activity in obese cats during a controlled weight loss programme [16].

Given the importance of obesity as a medical disease, and the recognition that current strategies are not perfect [18], there has been a great deal of recent interest in improving diets for controlled weight loss so as to improve outcomes. Indeed, in the last five years, new diets have been developed and become commercially available $[24,25]$, and many existing commercial weight loss diets have been reformulated [18]. As a result, there is a need to assess the efficacy of diets that are currently available. Therefore, the aim of the current study was to compare the performance, in terms of VFI and palatability, of novel commercially-available canine and feline weight loss diets, in groups of healthy dogs and cats housed in research colonies.

\section{Methods}

Research sites and study animals

The studies were undertaken between January 2014 and July 2014 at two sites: the Royal Canin Research Center,
Aimargues, France (Site 1), and the National Veterinary School of Nantes, Food Science and Engineering, (ONIRIS) France (Site 2). The first canine VFI study, the feline VFI study, and both the feline and canine palatability studies were all performed at site 1; the second canine VFI study was performed at site 2 . The participating cats and dogs were colony animals; those from site 1 were sourced from private breeders, whilst those from site 2 were born and raised at research site itself. All animals were deemed to be healthy prior to the start of the study, based upon health checks (comprising physical examination), and clinicopathological assessments (e.g. blood chemistries and complete blood counts), conducted on a monthly and annual basis, respectively. All remained healthy during the studies, with no adverse events were reported, and no modifications to any of the experimental protocols were required. Faecal consistency also remained throughout, albeit a greater volume was consistently produced on the test diets given the increased fibre content.

The first canine VFI study was undertaken in May 2014 and involved twelve healthy neutered female adult small breed dogs (5 Miniature Schnauzers, 5 Bichon Frisés, 1 Miniature Dachshund and 1 Cairn terrier), in ideal body condition (body condition score [BCS] 5/9), with a median age of 6y $8 \mathrm{mo}$ (range $3 \mathrm{y} 10 \mathrm{mo}$ to $13 \mathrm{y}$ 0mo). The second canine VFI study was undertaken in June 2014 and involved ten healthy beagle dogs (4 neutered females, 6 intact males) in ideal body condition (BCS 5/9), with a median age of 4 y 3 mo (range 2 y 8 mo to $6 y$ 0mo). The feline VFI study was undertaken in May 2014 and involved 12 healthy adult cats (7 neutered males and 5 neutered females), with a median age of $4 y$ $1 \mathrm{mo}$ (range $4 \mathrm{y} 0 \mathrm{mo}$ to $4 \mathrm{y} 3 \mathrm{mo}$ ). Nine of the cats were of the domestic shorthair breed, whilst the remaining 3 were Bengal. Median body condition score was 4/9 (range 4-8/9), with 10 cats being in ideal weight (BCS 4-5/9) and 2 cats being overweight (BCS 6/9 and 8/9).

The dog palatability study was undertaken in January 2014 and involved 37 healthy neutered female adult dogs (median age, $2 \mathrm{y} 10 \mathrm{mo}$, range $1 \mathrm{y} 2 \mathrm{mo}$ to $11 \mathrm{y} 5 \mathrm{mo}$ ) from various breeds including: Beauceron (1), Bernese Mountain Dog (2), Brittany Spaniel (1), Cairn Terrier (2), Cocker Spaniel (4), Dachshund (4), English Setter (2), Flat Coated Retriever (1), German Shepherd Dog (4), German Wirehaired Pointer (2), Gordon Setter (2), Irish Setter (1), Jack Russell Terrier (7), Miniature Schnauzer (1), Portuguese Podengo (1), and West Highland White Terrier (2). The cat palatability study was undertaken in July 2014 and involved 30 healthy adult cats (17 neutered females, 13 neutered males), with a median age of $7 y$ 0mo (range $3 y \quad 4$ mo to 14 y $5 \mathrm{mo}$ ), from various breeds including: Abyssinian (1), Bengal (2), Birman (4), Chartreux (1), Domestic Shorthair (12), Exotic Shorthair 
(2), Maine Coon (2), Oriental (1), Siamese (1), Somali (3), and Sphynx (1).

\section{Housing and husbandry}

Housing and treatment protocols adhered to European regulatory rules for animal welfare. At site 1, dogs were housed in groups of two in closed indoor-outdoor runs, the size of which varied depending upon the size of the dogs (indoor box size: 5.4-9.3 $\mathrm{m}^{2}$; outdoor run size: 3.6$12.5 \mathrm{~m}^{2}$ ). For the feeding studies, all dogs were fed individually, using separate 'traps' within their own pen. At site 2, dogs were housed in groups of 6 in outdoor runs of $20 \mathrm{~m}^{2}$, with half of the run being covered. Dogs also had free access to dog houses of $1.9 \mathrm{~m}^{2}$ (Dogloo $\mathrm{X}$ Large, Petmate, Arlington, USA). For the feeding studies, dogs were again fed individually, this time using individual pens of $4 \mathrm{~m}^{2}$. Cats were group-housed in closed indoor-outdoor runs, of $27 \mathrm{~m}^{2}$, with a maximum of 8 cats per run. The runs with outdoor access were divided into an indoor part (of $13 \mathrm{~m}^{2}$ ) and an outdoor part (of $14 \mathrm{~m}^{2}$ ). For the feeding studies, cats were fed using automated feeding stations (see below). Dependent on the season, the inside temperature varied between $18{ }^{\circ} \mathrm{C}$ and $24{ }^{\circ} \mathrm{C}$. For both dog and cat housing at site 1 , artificial light was provided in addition to the natural light, between 07.30 and 17.00, if natural light was judged to be insufficient by the animal caregivers. This was not the case for site two because of the use of outdoor runs. All dogs had exercise sessions of $2 \mathrm{~h}$ /day at site 1 and at least $1 \mathrm{~h}$ /day at site 2 . For cats, caregivers stimulated play behaviour for approximately $2 \mathrm{~h}$ per run, per day.

\section{Diets}

The VFI and palatability studies involved four complete and balanced diets, purpose-formulated for weight loss, two designed for feeding to dogs, and two for cats (Table 1). Diet C1 was a high protein high fibre diet (Satiety Weight Management Canine, Royal Canin, Aimargues, France), whilst diet $\mathrm{C} 2$ was a moderate protein high fibre diet (Prescription Diet ${ }^{\circ}$ Canine Metabolic Advanced Weight Solution, Hill's Pet Nutrition, Topeka, KS, USA). These two diets differed in energy content (average dietary composition based upon typical analysis: C1, $12041 \mathrm{KJ} / \mathrm{kg}$ [2876 kcal/kg]; C2, $12996 \mathrm{KJ} / \mathrm{kg}$ [3104 kcal/kg]) and macronutrient profile, with diet $\mathrm{C} 1$ containing more protein $(104 \mathrm{~g} / 1000 \mathrm{kcal}$ vs. $84 \mathrm{~g} / 1000 \mathrm{kcal})$ and fibre (crude fibre: $58 \mathrm{~g} / 1000 \mathrm{kcal}$ vs. $43 \mathrm{~g} / 1000 \mathrm{kcal}$ ), but less fat $(33 \mathrm{~g} / 1000 \mathrm{kcal}$ vs. $37 \mathrm{~g} / 1000 \mathrm{kcal})$ and nitrogen-free extract (NFE $101 \mathrm{~g} / 1000 \mathrm{kcal}$ vs. $113 \mathrm{~g} / 1000 \mathrm{kcal}$ ) than diet C2 (Table 1).

The ingredients used also varied, including fibre sources (C1: vegetable fibres, beet pulp and psyllium [husks and seeds]; C2: pea bran meal, tomato pomace, beet pulp, and powdered cellulose). The remaining two diets were designed for feeding to cats (diet F1: Satiety Weight Management Feline, Royal Canin Aimargues, France; Diet F2: Prescription Diet ${ }^{\oplus}$ Metabolic Feline, Hill's Pet Nutrition Topeka, KS, USA). Protein content was similar between diets (diet F1: $118 \mathrm{~g} / 1000 \mathrm{kcal}$, diet F2: $121 \mathrm{~g} / 1000 \mathrm{kcal}$ ), but diet F1 contained more fibre (crude fibre: F1, $48 \mathrm{~g} / 1000 \mathrm{kcal} ; \mathrm{F} 2,29 \mathrm{~g} / 1000 \mathrm{kcal}$; total dietary fibre: F1, $82 \mathrm{~g} / 1000 \mathrm{kcal}$; C2, $53 \mathrm{~g} / 1000 \mathrm{kcal}$ ) and NFE (F1: $100 \mathrm{~g} / 1000 \mathrm{kcal} ; \mathrm{F} 2: 93 \mathrm{~g} / 1000 \mathrm{kcal}$ ), and less fat (31 g/1000 kcal vs. $41 \mathrm{~g} / 1000 \mathrm{kcal})$, than diet F2. Dietary energy content was also less in diet F1 (F1: $12405 \mathrm{KJ} / \mathrm{kg}$ [2963 kcal/kg]) than in diet F2: $(14302 \mathrm{KJ} / \mathrm{kg}$ [3416 kcal/kg]). Again, ingredients varied amongst diets, most notably for fibre source (F1: vegetable fibres, chicory pulp, and psyllium [husks and seeds]; F2: powdered cellulose, tomato pomace, and beet pulp).

Finally, organoleptic properties of the diets also varied amongst diets, with differences including shape,colour, texture, and smell. Diets $\mathrm{C} 1$ and $\mathrm{F} 1$ had a round (pastille) shape, whilst diets C2 and F2 had a triangular prism shape. All diets were brown in colour, with the shade being marginally lighter for diets C2 and F2 compared with diets $\mathrm{C} 1$ and F1, respectively. None of diets were enriched with artificial colourings.

\section{Canine VFI studies}

Two studies were performed to determine VFI, with the first study using dogs from site 1 and the second study using dogs from site 2 . The design of each study was the same, except that different methods were used for calculating the metabolisable energy required for maintenance (MER; study 1: $110 \mathrm{Kcal} / \mathrm{kg}^{0.75} /$ day; study 2: $120 \mathrm{Kcal} / \mathrm{kg}^{0.75} /$ day), given differences in the known MER of each group. In each study, dogs were fed the two diets ( $\mathrm{C} 1$ and $\mathrm{C} 2$ ) for a period of 7 days, using a crossover design (Fig. 1), with half of the dogs receiving diet $\mathrm{C} 1$ first, and the other half receiving diet $\mathrm{C} 2$ first. The order of the diets was arbitraily decided in advance by the researchers, but did not used a formal method of randomisation. In order to minimise unwanted weight gain, the test protocol was performed on 3 non-consecutive days for each study period whilst, on the non-study days, food intake was reduced to $80 \%$ of MER (e.g. study 1: $88 \mathrm{Kcal} / \mathrm{kg}^{0.75}$; study 2: $96 \mathrm{Kcal} / \mathrm{kg}^{0.75}$ ). The two periods ran consecutively, with no adaptation period between diets. However, prior to the start of each study, all dogs had been offered both foods to familiarise them. On test days, consumption kinetics was assessed through repeated short-term food exposure, using a modification of a protocol previously described [20, 22]. Briefly, each dog was offered $110 \mathrm{kcal} / \mathrm{kg}^{0.75}$ for $15 \mathrm{~min}$ at 08:30 ( $1^{\text {st }}$ meal $)$ and again at 09:30 ( $2^{\text {nd }}$ meal $)$, and then offered food ad libitum for $15 \mathrm{~min}$ at both 10:30 


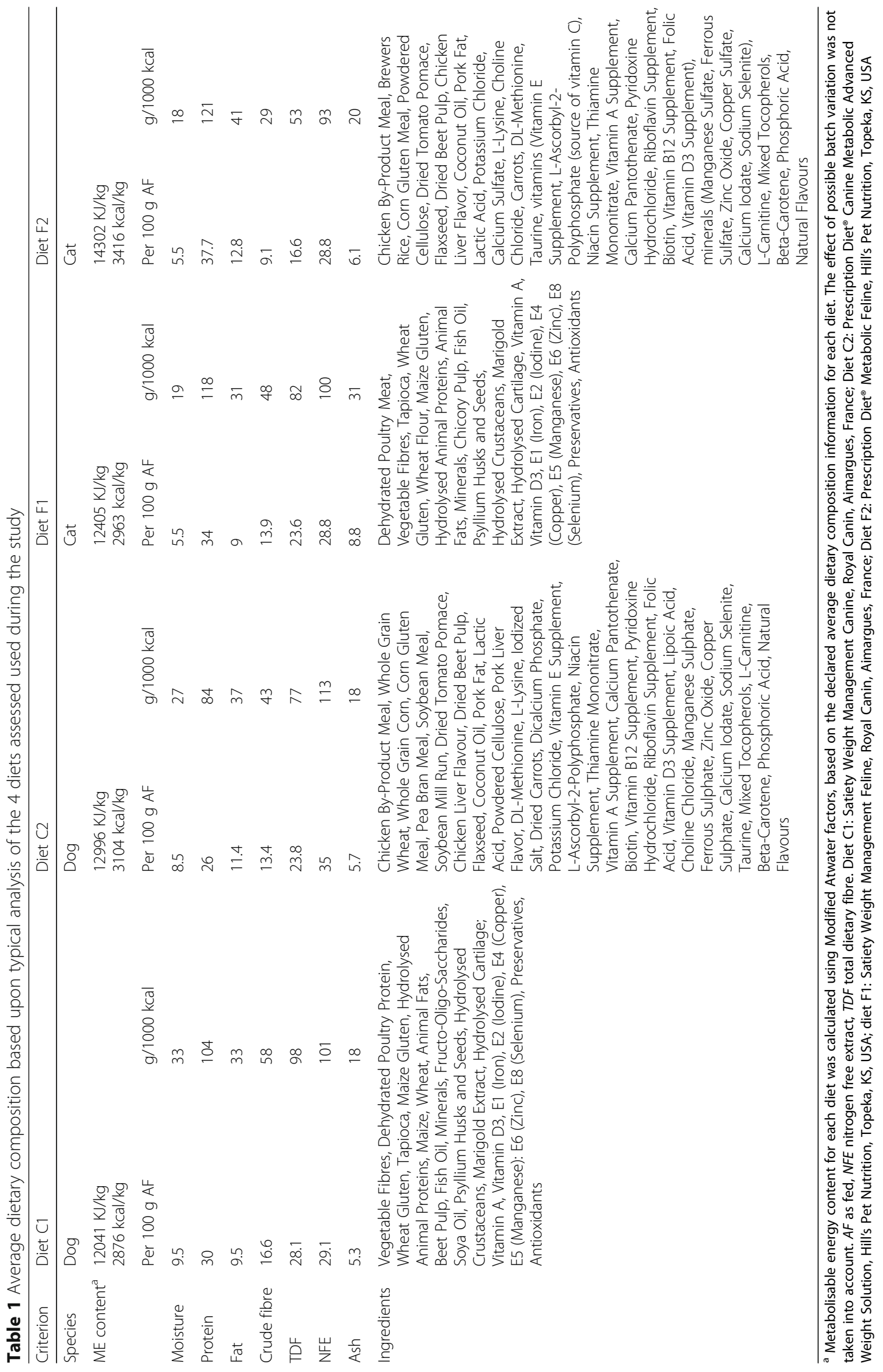




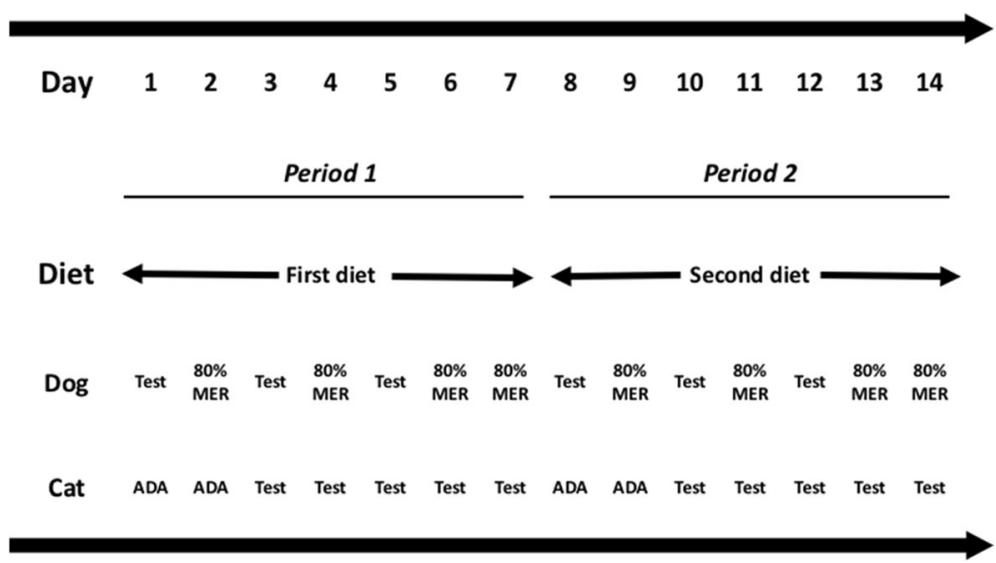

Fig. 1 Summary of the trial design for the voluntary food intake studies. For both canine studies, dogs were fed each diet, sequentially, for periods of 7 days. The test protocol (Test) was performed on 3 non-consecutive days for each study period, with food intake being limited to $80 \%$ of MER (e.g. study 1: $88 \mathrm{Kcal} / \mathrm{kg}^{0.75}$; study 2: $96 \mathrm{Kcal} / \mathrm{kg}^{0.75}$ ). For the feline voluntary food intake study, cats were fed each diet ad libitium, sequentially, for periods of 7 days, with each an initial 2-day adaptation phase (ADA) and then a 5-day test phase (Test)

$\left(3^{\text {rd }}\right.$ meal $)$ and 11:30 ( $4^{\text {th }}$ meal). At all meals, dogs left the bowl before the end of the 15-min feeding period, with most finishing eating within 5 min. Water was freely available for consumption at all times. Food intake was measured by weighing the bowl on calibrated electronic gram scales (Site 1: P8000-S, Mettler-Toledo, Albstadt, Germany; Site 2: NVT 160 000, OHAUS, Nänikon, Switzerland; both scales accurate to within $1 \mathrm{~g}$ ) before and after each meal to determine the amount of food eaten.

Body weight $(\mathrm{BW})$ was recorded on a weekly basis throughout the trial period using calibrated electronic weigh scales (Site 1: SG16000, Mettler Toledo; Site 2: SPIDER SW, Mettler Toledo, accurate to within $50 \mathrm{~g}$ ), and the mean bodyweight for this period was used to calculate the mean study metabolic body weight (MBW, e.g. $\mathrm{BW}^{0.75}$ in kg; NRC 2006). Energy intake at each meal was then calculated by multiplying the energy content of the food by the amount consumed, and then dividing this by the dog's average study MBW.

\section{Feline VFI study}

As with the canine study, cats were fed the two diets (F1 and F2), each for periods of 7 days, again using a crossover design (Fig. 2), with half of the cats receiving diet F1 first, and the other half receiving diet F2 first. Again, the order of the diets was arbitrarily decided in advance by the researchers. Each period consisted of an initial 2-day adaptation phase, and then a 5-day test phase. On each test day, the respective diet was offered ad libitum for a period of $18 \mathrm{~h}$, with no food being available for the remaining 6-h so as to limit excessive food consumption during the study. The period of food availability (between 14:00 and 08:00 on each test day) was selected to ensure that food was available for the known times of peak consumption within the colony (i.e. during the evening and early hours of the morning), and also fitted best with the daily routines of the animal caregivers. Water was freely available for consumption throughout the study. Each cat had access to its own food station by microchip recognition, and individual food intake (in grams) was recorded daily using electronic weigh scales (M-Tronic Paris; France; accurate to within $0.5 \mathrm{~g}$ ). Energy intake was then calculated by multiplying the energy content of the food by the amount consumed.

As with the canine study, body weight was recorded on a weekly basis throughout the study period using calibrated weigh scales SG16000; Mettler Toledo), and the mean body weight for the whole period used to calculate the mean study MBW (e.g. BW ${ }^{0.711}$ in kg; NRC 2006). Each cat's food energy intake was then expressed relative to MBW.

\section{Canine and feline palatability studies}

For the canine palatability study, a panel of 37 entire female dogs participated, all of which were routinely used in palatability testing at site 1 . A range of different sizes, breeds and ages were represented. The protocol was repeated on 2 consecutive meals on the same day, at 08:00 and 16:00 (M1, M2). For each test, the two diets were served, side-by-side in identical bowls, with the food allocated to each bowl arbitrarily decided. The amount provided in each bowl was equivalent to twice the energy requirements recommended for each dog. At the end of the 15-min test period, the amount of each food consumed by all dogs was measured.

A similar approach was chosen for the feline palatability study, although a panel of 30 cats participated. Again, this panel was routinely used for palatability testing, and a range of breeds, ages and genders was represented. The protocol was performed twice on two consecutive days, such that both diet (F1 vs. F2) and day (D1 vs. D2) effects were assessed. As with the canine study, the two diets 

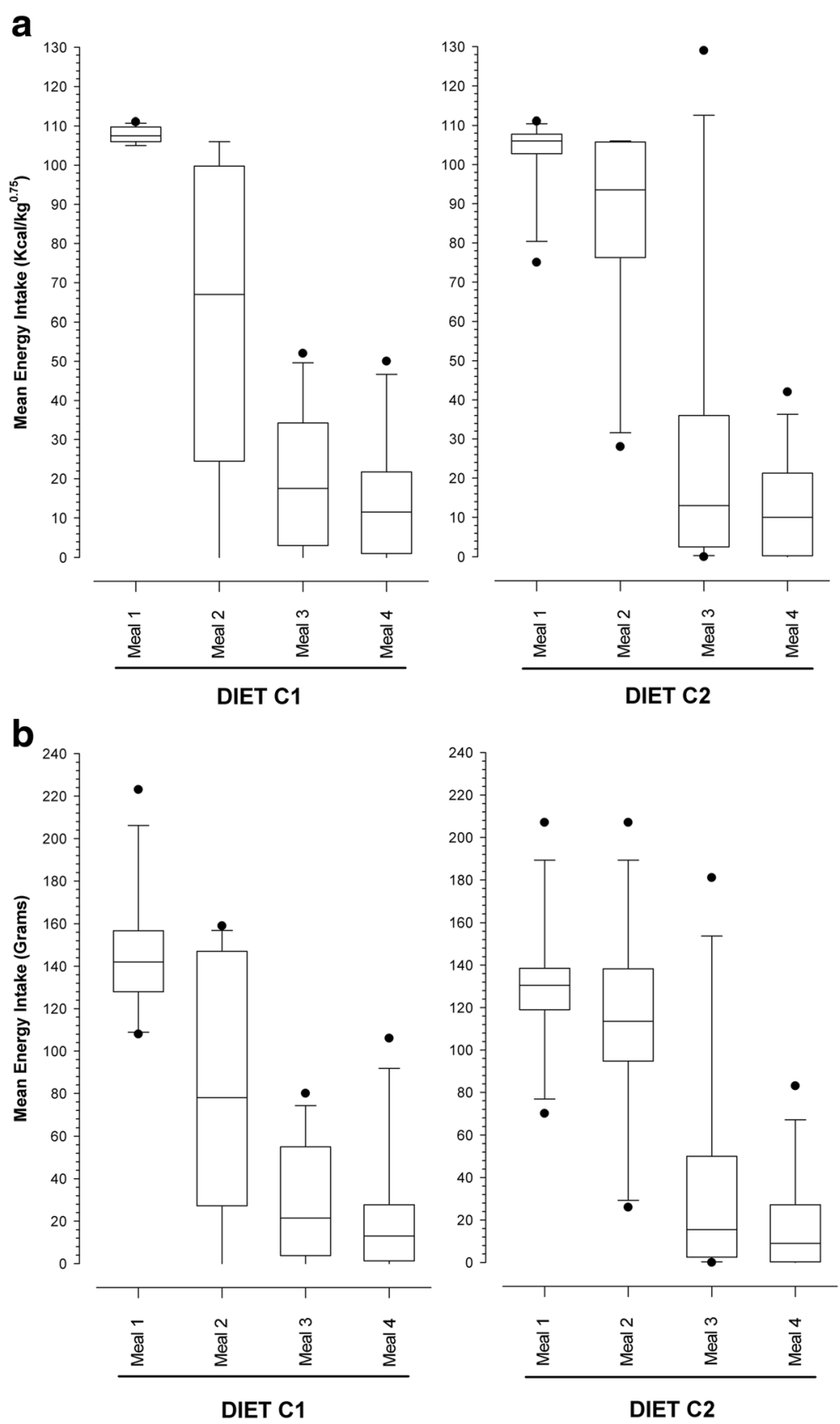

Fig. 2 Box and whisker plots of sequential energy (a) and gram weight (b) intake in the first canine voluntary food intake study (Study 1) where dogs were fed the two study diets (C1 and (2), over four meals. The boxes depict median (horizontal line) and inter-quartile range (top and bottom of box), the whiskers show the 10-90\% range, and outliers are shown as separate points. Each dog was offered $110 \mathrm{kcal} / \mathrm{kg}^{0.75}$ for $15 \mathrm{~min}$ at 08:30 (1 ${ }^{\text {st }} \mathrm{meal}$ ) and again at 09:30 ( $2^{\text {nd }}$ meal), and then offered food ad libitum for 15 min at both 10:30 ( $3^{\text {rd }}$ meal) and 11:30 ( $4^{\text {th }}$ meal). a A significant reduction of energy intake was observed between the second and third meals for both diets $(P<0.001)$, but between the first and second meals for diet $\mathrm{C} 1$ only $(C 1: P<0.001 ; C 2: P=0.256)$. A diet effect was also evident $(P=0.032)$, with the main difference being a lesser intake at meal two for $C 1$ compared with C2 $(P=0.006)$. b A significant reduction in gram weight intake of food was observed between the second and third meals for both diets $(P<0.001)$, but between the first and second meals for diet $\mathrm{C} 1$ only $(\mathrm{C} 1: P<0.001 ; \mathrm{C} 2: P=0.960)$. However, no difference in the gram weight intake of food was observed between diets $(P=0.964)$

were served, side-by-side in two identical bowls, with the food allocated to each bowl again arbitrarily determined. The amount of each food provided was equivalent to twice the energy requirements recommended for each cat.
However, cats had free access to both diets over a 22-hperiod (i.e. from 10:00 until 08:00). Food intake of both diets was again recorded using the same approach as for the canine palatability study. 


\section{Data handling and statistical analysis}

The sample sizes decided for the studies were not determined by use of a power analysis calculation. Instead, the group size used was equivalent to that used in previous studies assessing VFI and palatability [20, 22]. For the VFI studies, the primary outcome measure of interest was the amount of energy consumed (expressed both as $\mathrm{KJ}$ and $\mathrm{Kcal}$ per $\mathrm{kg}$ of $\mathrm{MBW}$ ), whilst secondary outcomes included the weight of food consumed (in grams), and also BW (in $\mathrm{kg}$ ) measured before and after each protocol (as described above). For the palatability studies, the primary outcome measure was the amount of each diet consumed in grams.

In all studies, complete data were available for all animals participating, except for one cat in the Feline VFI study whereby malfunction of the electronic food scales meant that the data could not be used. Data were recorded in a computer spreadsheet (Additional file 1; Excel For Mac version 15.28, Microsoft Inc.) and analysed using the Statistical Analysis Systems institute package (SAS version 9; SAS Institute Inc.). For the canine VFI, a linear mixed model assessing the fixed effects of diet (C1, C2) and meal (M1, M2, M3, M4), and their related interaction, on the food and energy intake of dogs. The variable 'dog' was defined as a random term. In a similar manner, a linear mixed model was used to assess the fixed effect of diet (F1, F2) on the food and energy intake of cats, with the variable 'cat' being included as a random term. Given the design of the palatability studies, the fixed effects of diet (C1, C2 for dogs; F1, F2 for cats) and either meal (M1, M2) for dogs or day (D1, D2) for cats with their related interaction were assessed on food intake. The variables 'dog' and 'cat' were included as random terms in the model.

In each case, when residuals of a model were not normally distributed at an alpha risk level of 1\% (ShapiroWilk and Kolmogorov-Smirnov tests), that output variable was rank-transformed prior to analysis to be treated in a non-parametric manner. Post-hoc analysis $P$-values were adjusted using Scheffe method to deal with alpha risk inflation linked to multiple comparisons. Unless indicated otherwise, all data are expressed as median (range). The level of significance was set at $5 \%$ for 2 -sided analyses.

\section{Results \\ Canine VFI studies \\ Study 1}

Before the study, BW was $5.82 \mathrm{~kg}(3.96-10.46 \mathrm{~kg})$, and was $6.09 \mathrm{~kg}(4.00-11.44 \mathrm{~kg})$, after the study. Despite the small but significant increase in bodyweight $(+0.12 \mathrm{~kg}$ $[+2.1 \%$, of starting BW], range -0.10 to $+0.98 \mathrm{~kg}[-2.4 \%$ to $+10.3 \%], P=0.016$ ), all dogs remained in ideal body condition (e.g. 5/9) throughout the study.
When food intake was assessed on an energy basis (Fig. 2a), a significant diet effect was evident $(P=0.032)$, with dogs consuming less of diet $\mathrm{C} 1\left(198 \mathrm{kcal} / \mathrm{kg}^{0.75}\right.$ [144$\left.\left.268 \mathrm{kcal} / \mathrm{kg}^{0.75}\right]\right)$ than of $\left(\mathrm{C} 2: 206 \mathrm{kcal} / \mathrm{kg}^{0.75}[121-\right.$ $\left.338 \mathrm{kcal} / \mathrm{kg}^{0.75}\right]$ ). Post-hoc analysis revealed the main difference in food intake to be at meal 2, where $42 \%$ less of $\mathrm{C} 1$ was eaten than $\mathrm{C} 2(P=0.006)$. An interaction was also seen between the diet and meal effects $(P<0.001)$, with the evolution of food intake over the successive meals differing between the two diets. Specifically, a significant reduction of energy intake was observed between the second and third meals for both diets $(P<0.001)$, but between the first and second meals for diet $\mathrm{C} 1$ only $(\mathrm{C} 1: P<0.001 ; \mathrm{C} 2: P=$ $0.256)$. Nevertheless, an overall decrease in food intake between meal 1 and meal 4 was also evident for both diets $(-86.5 \%, p<0.001 ;-88.1 \%, p<0.001$ for diets $\mathrm{C} 1$ and $\mathrm{C} 2$, respectively).

When food intake was instead assessed on a gram weight basis (Fig. 2b), the significant $\operatorname{dog}(P=0.016)$ and meal $(P<0.001)$ effects remained, but there was no longer a diet effect (total food intake on C1: $256 \mathrm{~g}$ grams [150-542 g]; total food intake on C2: $252 \mathrm{~g}$ [113-476 g]; $P=0.964)$. However, the diet-meal interaction was still evident $(P<0.001)$ with a significant gram weight reduction in food intake observed between the second and third meals for both diets $(P<0.001)$, but between the first and second meals for diet $\mathrm{C} 1$ only $(\mathrm{C} 1: P<0.001$; C2: $P=0.960$ ).

\section{Study 2}

Before the study, BW was $11.54 \mathrm{~kg}(9.46-14.16 \mathrm{~kg})$, $11.48 \mathrm{~kg}(9.60-14.28 \mathrm{~kg})$ after study period 1 , and $11.34 \mathrm{~kg}(9.38-14.52 \mathrm{~kg})$, after study period 2 . Bodyweight did not change significantly in this time $(P=$ $0.863)$, and all dogs remained in ideal body condition (e.g. 5/9) throughout.

When food intake was assessed on an energy basis (Fig. 3a), a significant diet effect was again evident $(P=$ $0.019)$ with dogs consuming less of diet C1 $\left(147 \mathrm{kcal} / \mathrm{kg}^{0.75}\right.$ $\left.\left[93-225 \mathrm{kcal} / \mathrm{kg}^{0.75}\right]\right)$ than of diet C2 $\left(189 \mathrm{kcal} / \mathrm{kg}^{0.75}[86-\right.$ $290 \mathrm{kcal} / \mathrm{kg}^{0.75}$ ]; $P=0.019$ ). As with study 1 , a significant meal effect was also observed $(P<0.001)$, with a significant reduction in intake occurring after each consecutive meal, except between the $3^{\text {rd }}$ and $4^{\text {th }}$ meals. Finally, a significant dog effect was also found $(P=0.046)$, but there was no dietmeal interaction $(P=0.434)$.

When food intake was instead assessed on a gram weight basis (Fig. 3b), the significant meal effect remained $(P<$ $0.001)$, but neither the $\operatorname{dog}(P=0.052)$ nor diet (total food intake on $\mathrm{C} 1$ : $318 \mathrm{~g}$ [202-487 g]; total food intake on C2: $380 \mathrm{~g}$ [173-582 g]; $P=0.255)$ effects were evident. In contrast to the results expressed on an energy basis, a dietmeal interaction was evident $(P=0.023$; diet $C 1$ : meal 1 vs. meal $2 P<0.001$; meal 2 vs. meal $3, P=0.278$; meal 3 vs. 

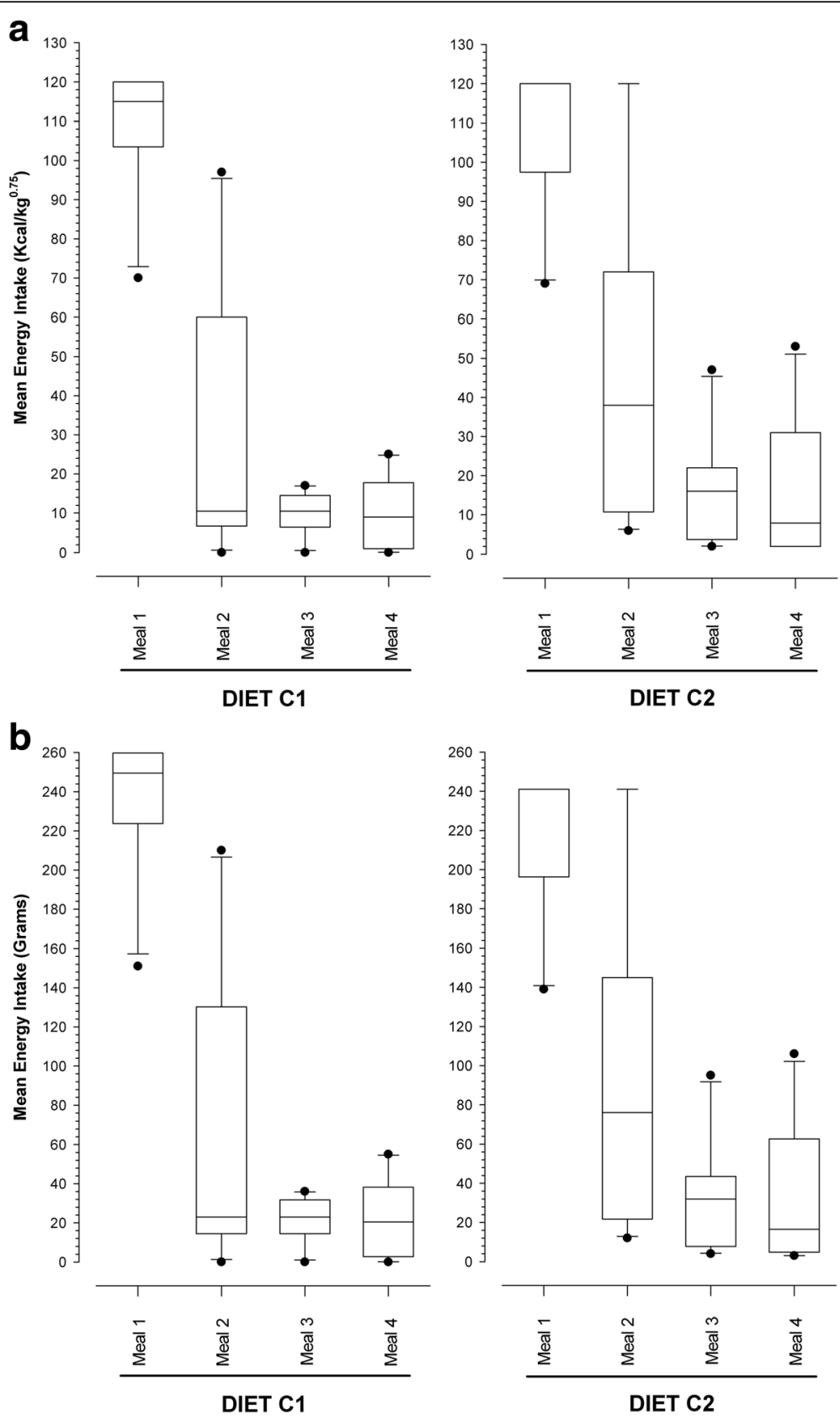

Fig. 3 Box and whisker plots of sequential energy (a) and gram weight (b) intake dogs in the second canine voluntary food intake study (Study 2) where dogs were fed the two study diets (C1 and C2), over four meals. The boxes depict median (horizontal line) and inter-quartile range (top and bottom of box), the whiskers show the 10-90\% range, and outliers are shown as separate points. a A significant reduction of energy intake was observed between the first and second $(P<0.001)$ and the second and third $(P<0.001)$ meals for both diets, but there was no difference in intake between the $3^{\text {rd }}$ and $4^{\text {th }}$ meals $(P=1.000)$. A diet effect was also evident $(P=0.019)$, with the main difference being a lesser intake at meal two for $C 1$ compared with $C 2(P=0.006)$. b A significant reduction in gram weight intake of food was observed between the first and second meals for both diets (C1: $P<0.001 ; C 2: P=0.009)$, but not between either the other meals. Further, no difference in the gram weight intake of food was observed between diets $(P=0.255)$

meal $4, P=1.000$; diet $C 2$ : meal 1 vs. meal $2 P=0.009$; meal 2 vs. meal $3, P=0.069$; meal 3 vs. meal $4, P=1.000$ ).

\section{Feline VFI study}

Prior to analysis, data from one cat were excluded on account of malfunction of the electronic food scales. Body weight prior to and after the studies was $4.32 \mathrm{~kg}$ (2.66$5.88 \mathrm{~kg})$ and $4.26 \mathrm{~kg}(2.67-5.81 \mathrm{~kg})$, respectively. There was no change in BW $(P=0.067)$ over the study period, and there was no change in BCS for any cat during this time.

During the course of the study, a diet effect was found when data were expressed on an energy basis $(P<0.001)$, 
with intake on diet F1 (55 Kcal $\left./ \mathrm{kg}^{0.711}, 0-143 \mathrm{Kcal} / \mathrm{kg}^{0.711}\right)$ being $17 \%$ less than intake when consuming diet F2 (66 $\left.\mathrm{Kcal} / \mathrm{kg}^{0.711}, 41-158 \mathrm{Kcal} / \mathrm{kg}^{0.711}\right)$. A significant cat effect was also evident $(P=0.023)$. When data were expressed on a gram weight basis, the cat effect remained $(P=0.023)$, but there was no longer a diet effect (F1: $51 \mathrm{~g}$ [0-127 g]; F2: $55 \mathrm{~g}[33-122 \mathrm{~g}] ; P=0.207)$.

\section{Palatability studies}

In the canine palatability test, the median intake of diets $\mathrm{C} 1$ and $\mathrm{C} 2$ was $41 \mathrm{~g}$ (range $0-350 \mathrm{~g}$ ) and $36 \mathrm{~g}$ (range 0$350 \mathrm{~g}$ ), respectively. Total food intake (combined intake of $\mathrm{C} 1$ and $\mathrm{C} 2$ for each $\operatorname{dog}$ ) during the study was $136 \mathrm{~g}$ $(26-427 \mathrm{~g})$. There was no significant meal effect $(P=$ $0.914)$ and no significant difference in food consumption between diets was observed $(P=0.490)$. In the feline palatability test, the median intakes of diets $\mathrm{F} 1$ and $\mathrm{F} 2$ were $30 \mathrm{~g}(0-66 \mathrm{~g})$ and $7 \mathrm{~g}(0-66 \mathrm{~g})$, respectively. Total food intake (combined intake of F1 and F2 for each cat) was $40 \mathrm{~g}(18-133 \mathrm{~g})$. No significant day effect was observed $(P=0.476)$, but there was a highly significant difference in consumption of the two diets $(P<0.001)$.

\section{Discussion}

In the current study, performance (in terms of VFI and palatability) of different commercially available purposeformulated canine and feline weight loss diets was assessed in groups of healthy dogs and cats in ideal body condition. There were significant differences in overall energy intake between the diets tested in both the canine and feline studies. These findings are important given that maximising satiety is a critical factor for any diet used in a controlled weight loss programme $[16,17]$.

The canine diets differed in energy content, macronutrient content, the sources of fibre, individual ingredients, and also in organoleptic properties. As a result, there could be various explanations for the observed differences. First, and most likely, the differences in energy intake could be due to differences in energy content because diet $\mathrm{C} 1$ was $8 \%$ less energy dense than diet $\mathrm{C} 2$. This explanation is supported by the fact that, when VFI was expressed on a gram weight basis (rather than on an energy basis), the diet effect was no longer evident. Against this, however, a diet-meal interaction was also observed: whilst, intake for both diets tended to decrease steadily across the four meals, differences in the pattern between diets was observed, most notably with a lower intake on $\operatorname{diet} \mathrm{C} 1$ at meal 2. It is difficult to reconcile such a meal effect if the energy intake difference was simply due to relative energy dilution. Further, in a previous study with a similar design, the diet that was consumed least did not have the lowest energy content [22]. This suggests that factors in addition to energy dilution might be responsible for the observed differences in energy intake on the two diets. Other possible reasons could include differences in macronutrient content, specifically protein and fibre content, as previously demonstrated $[17,22]$. Relative to energy content, diet $\mathrm{C} 1$ had $19 \%$ more protein and $21 \%$ more fibre than diet $\mathrm{C} 2$, which is equivalent to the differences between the 3 diets used in a previous study [22]. This again suggests that foods containing more protein and fibre have the best satiety, an observation supported by human studies [26-30].

As for the canine studies, no differences in VFI were seen between feline diets when measured by the gram weight, but cats consumed $17 \%$ less, of diet F1 compared with diet F2, when intake was expressed on an energy basis. Like the canine diets, the feline diets differed in energy (F1 15\% less than F2) and total dietary fibre content (F1 35\% more than F2). However, in contrast to the canine diets, protein content was similar between the feline diets, and diet $\mathrm{F} 1$ also contained 32\% less dietary fat than F2. Finally, there were also differences in the type of fibre included and the ingredient lists for the two diets. Whatever the reason for the diet effect on voluntary energy intake, the results do suggest differences in the satiety effect between weight loss diets in cats, supporting the findings of other studies whereby the same diet resulted in less marked begging behaviour than other diets in obese cats during weight loss [16].

With regard to fibre type, the main fibre sources in the canine and feline diets where energy intake was least were vegetable fibres, beet pulp, psyllium and chicory pulp (F1 only), whilst the fibre used in the diets where energy intake was greatest was pea bran meal, tomato pomace, beet pulp, and powdered cellulose. Fibre types can differ greatly in their properties, leading to highly variable influences on water binding, gastric emptying, and the viscosity of the digesta, thus exerting different effects on VFI. Indeed, studies undertaken in humans have shown that psyllium improves satiety [31-33]. For instance, the vegetable fibre used in diet F1 contains cellulose with a high water binding capacity, and this could help delay gastric emptying explaining the improved satiety. More details about the exact fibre blends used for each diet might have shed light on their specific properties. However, since the diets used are sold commercially, such details constitute proprietary information and therefore are not publicly available. Therefore, it was not possible to fully assess the relative effects of fibre type and other factors (such as macronutrient content and energy density), and this is acknowledged as a study limitation. Nonetheless, the advantage of using commercially-available diets was the fact that the results would be more directly relevant to clinical practice.

One possible explanation for a difference in VFI between two diets, is if they differ in palatability and, for this reason, food preference tests were also performed. 
The palatability of the two canine diets was equivalent, whilst the feline diet that was least consumed was found to be significantly more palatable. In light of these findings, palatability differences amongst diets are not likely to account for study results, and the effect of the F1 diet on VFI in cats may well be even more pronounced given this superior palatability. In contrast, no differences in palatability were seen between the two canine diets, again suggesting that this is unlikely to be the reason for the differences in VFI between diets $\mathrm{C} 1$ and $\mathrm{C} 2$. However, it should be noted that this palatability study was conducted in Winter, whilst, all other studies (including the feline palatability study) were conducted in springsummer. It is unclear whether this difference might have affected the results obtained.

Different designs were used to assess VFI in the canine and feline experiments. Dogs can consume large amounts of food in a single sitting, whilst cats prefer to consume food in multiple meals throughout the day, with each meal being small [34]. For this reason, the canine experiments involved assessing short-term VFI by monitoring food consumption kinetics in a 4-h period, based upon a design used in a previous study [22]. In contrast, daily VFI was measured in cats using automated food stations, again, as previously reported [23]. The use of such food stations, which recognised individual cats, allowed individual cats to consume food in whatever meal pattern they preferred during the study period, whilst ensuring that the amount consumed was accurately and precisely measured. In the authors' opinion, the use of such devices is essential for assessing VFI in this species, and would recommend them for all future studies.

As with any study, a number of limitations must be considered in addition to those detailed above. First, studies used small groups of dogs and cats housed in colonies rather than pet dogs and cats in their home environment. Thus, results might not be generalisable to the larger pet population that would have greater inherent variability in terms of animal factors, environment and the fact that they would be client-owned. That said, the advantage of using colony animals was the fact that experimental conditions could be better controlled and study parameters such as food intake and palatability more precisely measured. Second, the replicate experiments for the canine VFI study were undertaken at different sites, using different dogs and housing conditions. Although the results were broadly similar, there was some variability observed. Third, also for the canine VFI studies, no adaptation period was included between the test periods for each. This might have affected the feeding kinetics of the study, although it is unclear as to whether any systematic bias resulted because the order in which diets were fed was arbitrarily decided.
A fourth study limitation was the fact that all of the VFI studies were short term in nature, and it is not known whether the satiating effect wanes when a restricted diet is fed continually. Similarly, the palatability studies were only conducted over two consecutive meal periods (two meals in a single day for dogs; two 22-h periods on consecutive days for cats), and thus did not assess whether taste preferences might have changed with time.

Finally, the study did not assess diet performance in overweight pet dogs and cats during energy restriction in order to induce controlled weight loss; instead, healthy research colony animals in optimal body condition were used and none of them lost weight during the study. Therefore, the results of the current study may not be generalisable to the target population. The main reason for our choice of research colony animals over pet animals was a far greater ability to control experimental conditions, thus improving accuracy of results and reducing the number of animals required to participate. Whilst not impossible, it would have been logistically difficult to perform similar studies in overweight pet dogs in their own homes. In this respect, the study population would inevitably have been far more variable, for example differing in the degree of obesity, energy restriction required for weight loss, and in terms of concurrent illness present [19]. There would also have been more variability in housing conditions with differences in ambient temperature, lighting, and space available. Husbandry practices would have differed markedly for example the timing and method of feeding, provision of water, the exercise undertaken, and also participation in play activity. Owner factors would also be a consideration, with concerns over compliance with the study protocol [14, 15, 18]. Moreover, there would likely have variability in experimental conduct when extrapolated to the home environment and a greater likelihood of errors made in the timing of meals and measurement of food consumption. Finally, the use pet animals would have introduced ethical considerations; although none of the procedures were invasive adverse effects making adverse effects on welfare unlikely, it is questionable as to whether the animals would have benefitted from participating in the study. All-in-all, therefore, despite the inevitable limitations of using healthy colony animals, this approach was preferred. Whilst caution should be exercised when generalising our results to the wider pet population, the results are nevertheless interesting, suggesting that diets $\mathrm{C} 1$ and $\mathrm{F} 1$ would perform better and reduce unwanted begging activity in pets animals, as seen in a previous field study [16]. Nonetheless, further studies would now be needed in order to assess these diets under field conditions in obese dogs and cats undergoing controlled weight loss. 


\section{Conclusion}

In summary, the results of the experiments in the current study have demonstrated differences in voluntary energy intake in both cats and dogs when consuming commercially available weight loss diets. Possible explanations for the superior performance of diet C1 (vs. diet C2) include decreased energy content, increased protein and fibre content, and/or using psyllium and beet pulp as the fibre sources. In contrast, the possible explanations for the superior effect of diet F1 (vs. diet F2) include decreased energy and fat content, increased dietary fibre content, and/or using psyllium and chicory pulp as the main fibre sources. Further studies are now recommended so as to assess the performance of these weight loss diets in obese pet dogs and cats during a controlled weight loss programme.

\section{Additional file}

Additional file 1: Computer spreadsheet containing data from all studies. (XLSX $36 \mathrm{~kb}$ )

\section{Abbreviations}

BCS: Body condition score; BW: Body weight; MBW: Metabolic body weight; MER: Metabolisable energy required for maintenance; NFE: Nitrogen-free extract; ONIRIS: Nutrition and Endocrinology Unit, National Veterinary School of Nantes; SAS: Statistical analysis systems; VFI: Voluntary food intake

\section{Acknowledgements}

The authors thank the staff at the Nutrition and Endocrinology Unit, Oniris, National School of Veterinary Médecine, Food, Science and Engineering, France, for hosting dog study 2. All caregivers are also acknowledged for providing husbandry for all participating animals.

\section{Funding}

All research studies described were funded by Royal Canin.

\section{Availability of data and materials}

All data generated or analysed during this study are included in this published article, and its supplementary information files (Additional file 1).

\section{Authors' contributions}

MAH Designed the study, analysed the results, reviewed the manuscript. ES Designed the study, collected data. AJ-C Designed the study, collected data. AF Designed the study, analysed the data. DM Designed the study, reviewed the manuscript. ID Designed the study, reviewed the manuscript. VB Reviewed the study results. Reviewed the manuscript. SS Discussed clinical data, reviewed the manuscript. YQ Contributed to discussions on study design, reviewed the manuscript. AJG Reviewed the study results, wrote the initial draft of the manuscript. All authors have approved the final article.

\section{Competing interests}

The diets tested were commercially available; Royal Canin manufactures two of the diets studied (one cat and one dog), which were compared with two diets (one cat and one dog) manufactured by a competitor. All but one of the authors (Hours, Sagols, Junien-Castagna, Feugier, Moniot, Daniel, Biourge, Serisier, Queau) are current or past employees of this company. The remaining author (Alex German) is an employee of the University of Liverpool, but his post is financially supported by Royal Canin. All the authors were involved in the study design, in the collection, analysis and interpretation of data, in the writing of the manuscript, and in the decision to submit the manuscript for publication.

\section{Consent for publication}

Not applicable.

\section{Ethics approval and consent to participate}

All experimental protocols complied with European Union guidelines on animal welfare and were approved by the Royal Canin Committee for Animal Ethics and Welfare. Since all studies were undertaken in research colony animals from the institutions of the authors, no informed consent was required from owners.

\section{Author details}

${ }^{1}$ Royal Canin Research Center, Aimargues, France. ${ }^{2}$ Unité de Nutrition et d'Endocrinologie, Oniris, Nantes, France. ${ }^{3}$ Institute of Ageing and Chronic Disease, University of Liverpool, Leahurst Campus, Chester High Road, Neston, Wirral CH64 7TE, UK. ${ }^{4}$ Université de Nantes, Faculty of Dental Surgery, 1 Place Alexis Ricordeau, 44042 Nantes, France. ${ }^{5}$ Institute of Veterinary Science, University of Liverpool, Leahurst Campus, Chester High Road, Neston CH64 7TE, UK.

Received: 18 November 2015 Accepted: 28 November 2016

Published online: 05 December 2016

\section{References}

1. Kealy RD, Lawler DF, Ballam JM, Mantz SL, Biery DN, Greeley EH. Effects of diet restriction on life span and age-related changes in dogs. J Am Vet Med Assoc. 2002;220:1315-20.

2. Lund EM, Armstrong PJ, Kirk CA, Klausner JS. Prevalence and risk factors for obesity in adult dogs from private US veterinary practices. Int J Appl Res Vet Med. 2006:4:177-86.

3. German AJ, Ryan VH, German AC, Wood IS, Trayhurn PJ. Obesity, its associated disorders and the role of inflammatory adipokines in companion animals. Vet J. 2010;185:4-9.

4. Mosing M, German AJ, Holden SL, MacFarlane P, Biourge V, Morris PJ, Iff I. Oxygenation and ventilation characteristics in obese sedated dogs before and after weight loss: a clinical trial. Vet J. 2013;198:367-71.

5. German AJ, Holden SL, Wiseman-Orr ML, Reid J, Nolan AM, Biourge V, Morris PJ, Scott EM. Quality of life is reduced in obese dogs but improves after successful weight loss. Vet J. 2012:192:428-34.

6. Marshall WG, Hazelwinkel HAW, Mullen D, De Meyer G, Baert K, Carmichael $\mathrm{S}$. The effect of weight loss on lameness in obese dogs with osteoarthritis. Vet Res Comm. 2010;34:241-53

7. Tvarijonaviciute A, Ceron JJ, Holden SL, Morris PJ, Biourge V, German AJ. Obesity-related metabolic dysfunction in dogs: a comparison with human metabolic syndrome. BMC Vet Res. 2012;8:147.

8. Tvarijonaviciute A, Ceron JJ, Holden SL, Morris PJ, Biourge V, German AJ. Effect of weight loss in obese dogs on indicators of renal function or disease. J Vet Intern Med. 2013:27:31-8.

9. Laflamme DP, Kuhlman G. The effect of weight-loss regimen on subsequent weight maintenance in dogs. Nutr Res. 1995;15:1019-28.

10. Borne AT, Wolfsheimer KJ, Truett AA, Kiene J, Wojciechowski T, Davenport DJ, Ford RB, West DB. Differential metabolic effects of energy restriction in dogs using diets varying in fat and fiber content. Obes Res. 1996;4:337-45.

11. Diez M, Nguyen $P$, Jeusette I, Devois C, Istasse L, Biourge V. Weight loss in obese dogs: evaluation of a high-protein, low-carbohydrate diet. J Nutr. 2002;132:1685S-7S.

12. Nguyen $P$, Leray $V$, Dumon $H$, Martin L, Siliart B, Diez M, Biourge V. High protein intake affects lean body mass but not energy expenditure in nonobese neutered cats. J Nutr. 2004;134:2084S-6S.

13. Laflamme DP, Hannah SS. Increased dietary protein promotes fat loss and reduces loss of lean body mass during weight loss in cats. Int J Appl Res Vet Med. 2005;3:62-8.

14. German AJ, Holden SL, Bissot T, Hackett RM, Biourge V. Dietary energy restriction and successful weight loss in obese client-owned dogs. J Vet Intern Med. 2007;21:1174-80.

15. German AJ, Holden S, Bissot T, Morris PJ, Biourge V. Changes in body composition during weight loss in obese client-owned cats: loss of lean tissue mass correlates with overall percentage of weight lost. J Fel Med Surg. 2008;10:452-9.

16. Bissot T, Servet E, Vidal S, Deboise M, Sergheraert R, Egron G, Hugonnard M, Heath SE, Biourge V, German AJ. Novel dietary strategies can improve the outcome of weight loss programmes in obese client-owned cats. J Fel Med Surg. 2010;12:104-12.

17. German AJ, Holden SL, Bissot T, Morris PJ, Biourge V. A high-protein highfibre diet improves weight loss in obese dogs. Vet J. 2010;183:294-7. 
18. German AJ, Titcombe J, Holden SL, Queau Y, Morris PJ, Biourge V. A cohort study of the success of controlled weight loss programs for obese dogs. J Vet Intern Med. 2015;29:1547-55. doi:10.1111/jvim.13629.

19. German AJ, Andrews A, Holden SL, Morris PJ, Biourge V. Does concurrent disease influence the success of weight management in obese dogs? Birmingham: 57th British Small Animal Veterinary Association Congress; 2014

20. Serisier S, Pizzagalli A, Leclerc L, Feugier A, Nguyen P, Biourge V, German AJ. Increasing volume of food by incorporating air reduces energy intake. J Nutr Sci. 2014;3:e59.

21. Alexander JE, Colyer A, Morris PJ. The effect of reducing dietary energy density via the addition of water to a dry diet, on body weight, energy intake and physical activity in adult neutered cats. J Nutr Sci. 2014;3:e21.

22. Weber M, Bissot T, Servet E, Sergheraert R, Biourge V, German AJ. A highprotein, high-fiber diet designed for weight loss improves satiety in dogs. J Vet Intern Med. 2007:21:1203-8.

23. Servet E, Soulard Y, Venet C, Biourge V, German AJ. Ability of diets to generate 'satiety' in cats. J Vet Int Med. 2008;22:1482.

24. Floerchinger AM, Jackson MI, Jewell DE, MacLeay JM, Hahn KA, PaetauRobinson I. Effect of feeding a weight loss food beyond a caloric restriction period on body composition and resistance to weight gain in cats. J Am Vet Med Assoc. 2015;247:365-74.

25. Floerchinger AM, Jackson Ml, Jewell DE, MacLeay JM, Hahn KA, PaetauRobinson I. Effect of feeding a weight loss food beyond a caloric restriction period on body composition and resistance to weight gain in dogs. J Am Vet Med Assoc. 2015;247:375-84.

26. Blundell JE, Burley VJ. Satiation, satiety and the action of fibre on food intake. Int J Obes. 1987;11 Suppl 1:9-25.

27. Stubbs RJ. Macronutrient effects on appetite. Int J Obes Relat Metab Disord. 1995;19(Suppl):S11-9.

28. Louis-Sylvestre J. Toutes les protéines ont-elles le même pouvoir satiétogène? Cah Nutr Diet. 2002;37:313-21.

29. Gerstein DE, Woodward-Lopez G, Evans AE, Kelsey K, Drewnowski A. Clarifying concepts about macronutrients' effects on satiation and satiety. J Am Diet Assoc. 2004;104:1151-3.

30. Bowen J, Noakes M, Clifton PM. Effect of calcium and dairy foods in high protein, energy-restricted diets on weight loss and metabolic parameters in overweight adults. Int J Obes. 2005;29:957-65.

31. Bergmann JF, Chassany O, Petit A, Triki R, Caulin C, Segrestaa JM. Correlation between echographic gastric emptying and appetite: influence of psyllium. Gut. 1992;33:1042-3

32. Turnbull WH, Thomas HG. The effect of a plantago ovata seed containing preparation on appetite variables, nutrient and energy intake. Int J Obes Relat Metab Disord. 1995;19:338-42.

33. Rigaud D, Paycha F, Meulemans A, Merrouche M, Mignon M. Effect of psyllium on gastric emptying, hunger feeling and food intake in normal volunteers: a double blind study. Eur J Clin Nutr. 1998:52:239-45.

34. Ad Hoc Committee on Dog and Cat Nutrition, National Research Council. Feeding behaviour of dogs and cats. In: Nutrient requirements of dogs and cats. Washington DC: National Academies Press; 2006. p. 22-7.

\section{Submit your next manuscript to BioMed Central and we will help you at every step:}

- We accept pre-submission inquiries

- Our selector tool helps you to find the most relevant journal

- We provide round the clock customer support

- Convenient online submission

- Thorough peer review

- Inclusion in PubMed and all major indexing services

- Maximum visibility for your research

Submit your manuscript at www.biomedcentral.com/submit 